\title{
Myocardial Infarction Related To Iatrogenic Coronary Cameral Fistula in a Heart Transplant Patient
}

Zakaria Raiss $\mathrm{MD}^{1}$, Badre El Boussaadani $\mathrm{MD}^{1 *}$, Qat Amine $\mathrm{MD}^{2}$, Goube Pascal $\mathrm{MD}^{1}$

${ }^{1}$ Sud Francilien Hospital, France

${ }^{2}$ Cardiology B Department of CHU Ibn Sina, Rabat, Morocco

DOI: $10.36347 /$ sjmcr.2020.v08i03.034

| Received: 24.02.2020 | Accepted: 02.03.2020 | Published: 24.03.2020

*Corresponding author: EL Boussaadani Badre

\section{Abstract}

Endomyocardial biopsy (EMB) remains the gold standard method for diagnosis of cardiac allograft rejection. Complications following EMB rarely occur, however, it can lead to coronary cameral fistulae (CCF). We describe the case of a 65-year-old patient admitted for lateral STEMI related to a fistula communicating the distal part of the left anterior descending artery (LAD) with the right ventricle after EMB biopsy, which was successfully treated with a covered stent.

Keywords: Myocardial Infarction Iatrogenic Coronary Cameral.

Copyright @ 2020: This is an open-access article distributed under the terms of the Creative Commons Attribution license which permits unrestricted use, distribution, and reproduction in any medium for non-commercial use (NonCommercial, or CC-BY-NC) provided the original author and source are credited.

\section{INTRODUCTION}

Coronary cameral fistulae $[\mathrm{CCF}]$, which drains directly into the right ventricle are recognized as a complication of endomyocardial biopsy (EMB) [1 2], which is considered as the gold standard method for screening rejections in orthotopic heart transplant recipients [3]. Fistula can progress to spontaneous closure, or become larger and lead to myocardial ischemia. We report a case of myocardial infarction related coronary cameral fistula after right ventricular EMB in a heart transplant patient. A covered stent was inserted percutaneously, thus partially sealing off the fistula.

\section{Case RePORT}

A 65-year-old patient; with a history of ischemic cardiomyopathy since 2007 complicated by refractory heart failure despite medical optimization; underwent orthotopic heart transplantation in 2018. One month later, a post-operative complete heart block occurs justified a double chamber pacemaker implantation.

Three months after the transplantation, the patient was admitted for a checkup EMB. During his cardiac rehabilitation, 3 days after the procedure, he suffered from atypical chest pain. A 12 lead ECG showed new onset ST segment elevation of $2 \mathrm{~mm}$ over the lateral precordial leads, compatible with lateral myocardial infarction. A coronary angiogram showed a large fistula draining from the distal part of the LAD to the right ventricle (Figure 1).

Trans-thoracic echocardiography (Figure 2) showed apical akinesis associated with an abnormal diastolic flow into the RV apex/apical septum, very suggestive of a CCF. 


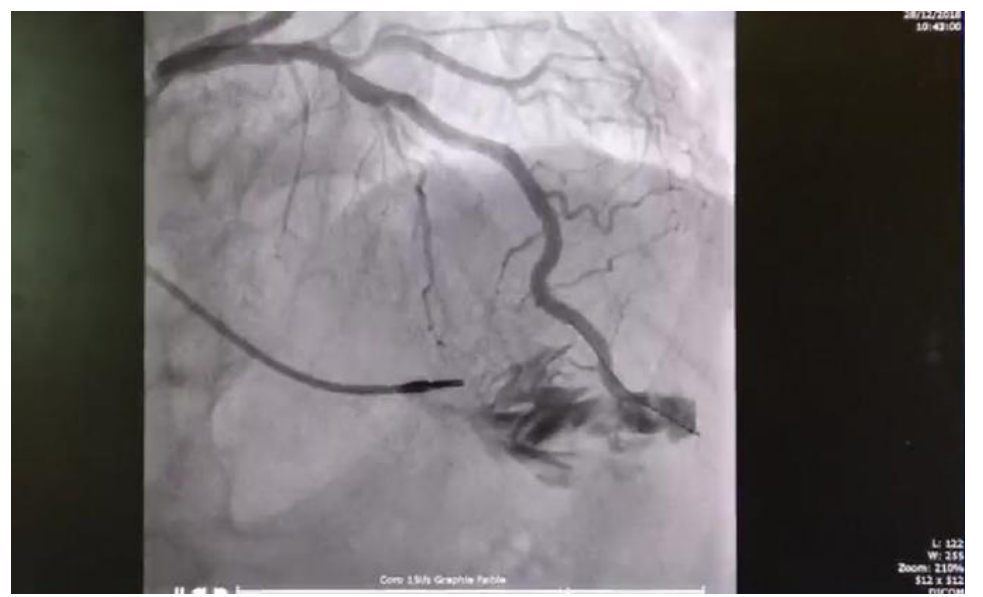

Fig-1: Right anterior oblique coronary angiogram (OAD) showing a fistula connecting distal LAD to the right ventricle

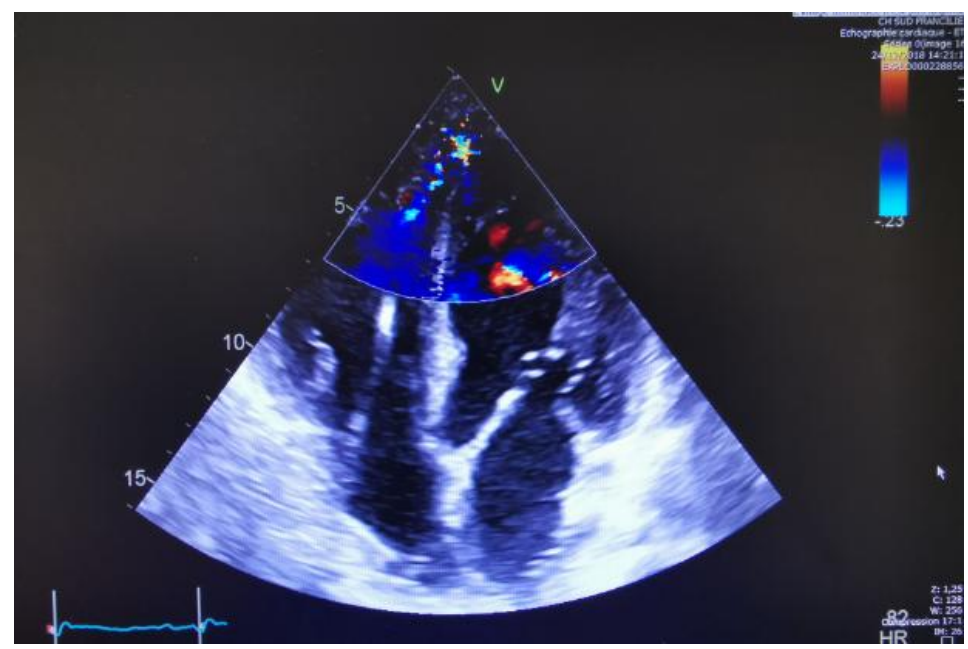

Fig-2: Apical 4-chamber view 2D image (left) and color doppler (right) demonstrating fistula (single arrow) and diastolic flow (double arrow) into the Right Ventricle $(\mathbf{R V})$

Percutaneous closure was attempted, due to the hemodynamically significant fistula, and the procedure was performed using the right femoral approach with a 7-F3,5. Extra Back up guiding catheter was positioned with microcatheter in distal LAD, predilatation by balloon $1.5 \mathrm{~mm}$ then $2.5 \mathrm{~mm}$, verification of the occlusion of the fistula (Figure 3) and a $2.5 \times 16 \mathrm{~mm}$ covered stent type begraft was deployed. The final result was the reappearance of a small shunt after disinflation of the balloon (Figure 4).

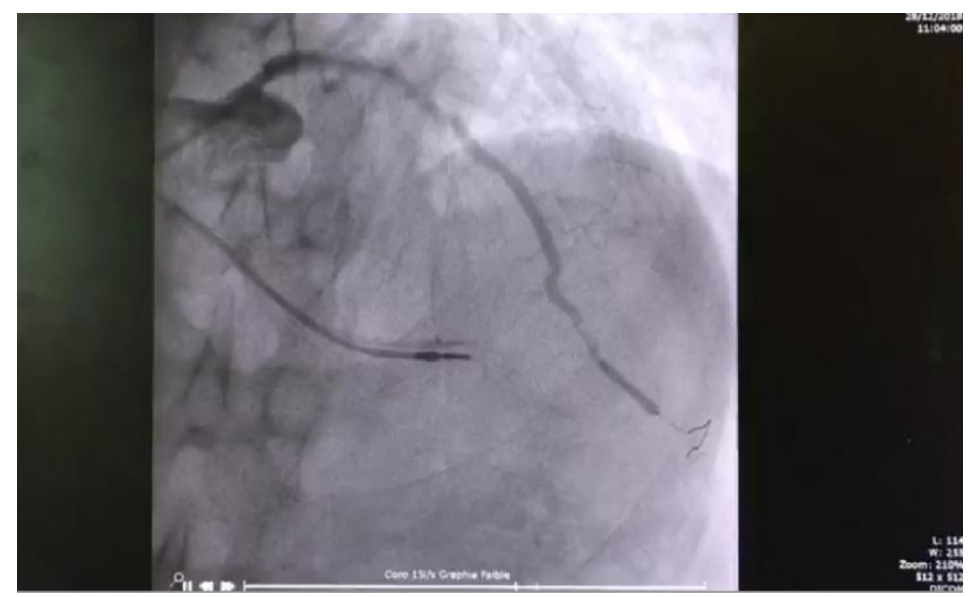

Fig-3: Occlusion of distal Left Anterior Descending Artery (LAD) at fistula, improved flow in distal LAD after deployment of stent 


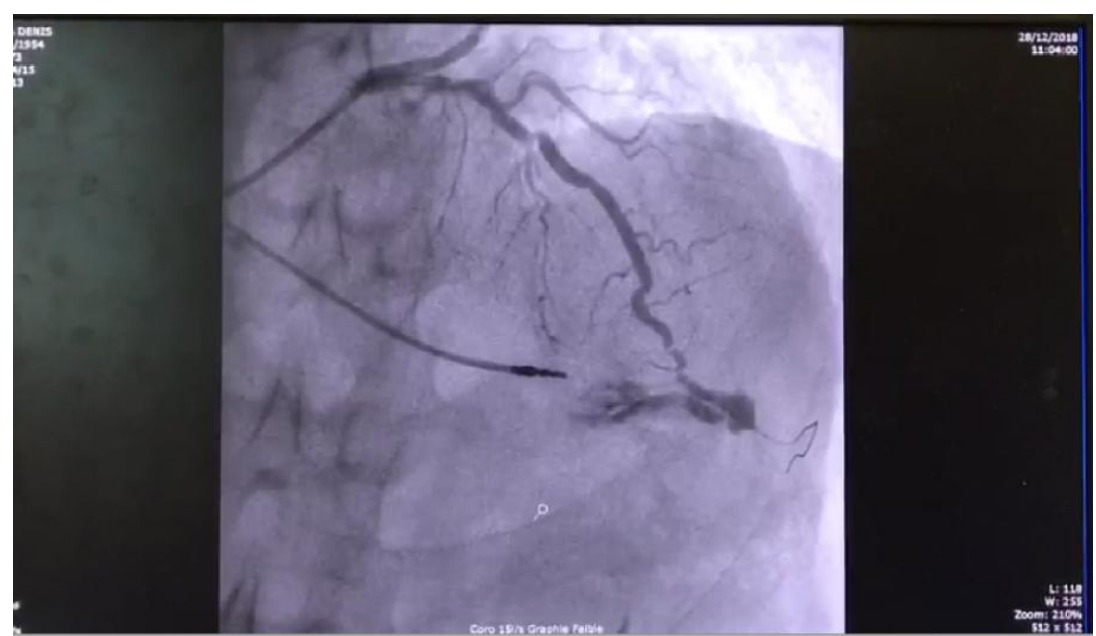

Fig-4: Reappearance of a small shunt after disinflation of the balloon

\section{DisCUSSION}

Cardiac transplantation is an effective therapy for many patients with end-stage heart failure. Rejection is a serious problem after transplant, thus most patients undergo repeated EMB in order to detect early rejection [4].

Coronary artery fistulae are rare abnormalities of the coronary arteries with an incidence of $0.08-0.3 \%$ [5]. They can be congenital or acquired .Congenital CAF are due to an embryologic standby, leading to other communications inside the heart or through major vessels. On the other hand, acquired CAF happen after trauma or may also be iatrogenic, related to EMB in less degree, and sometimes by accidental procedural bypass of the vein instead of the artery. In this case, the location of the fistula from the distal LAD to the right ventricle is very suggestive of an acquired etiology, which may be explained by multiples traumatic biopsies of the heart, during check-ups.

Case series report up to a $21 \%$ incidence of acquired $\mathrm{CAF}$ in heart transplant patients [6]. The majority of CAFs was diagnosed in angiography following a 1 year transplant, and is believed to be of iatrogenic cause.

The majority of the fistulas are linked to either the RCA or LAD artery, the latter being the case in our patient. Additionally, the circumflex coronary artery (CX) is sometimes also affected (RCA in approximately $55 \%$ of cases, LCA in $35 \%$, and both in 5\%) [7]. In most cases, it drains to the right ventricle.

The natural history of coronary fistulas due to EMB in heart transplant patients is usually benign [8], and conservative management approach is common. Different outcomes have been reported where some fistulas increase in size, while others remain unchanged, and better, some even resolving spontaneously. Moreover, despite the above-mentioned theoretical complications of CAFs, few were reported in literature [6].

Elective closure of the fistula can be performed if it is associated with a hemodynamically significant shunt or in case of symptoms, such as heart failure, arrhythmias, ischemia due to myocardial steal, thrombosis with embolization, or endocarditis.

Data on treatment intervention for $\mathrm{CAF}$ is scarce. The majority of available long-term data is attributed to congenital CAF. In fact, congenital CAF that are found fortuitously in adult patients have been treated with ligation, coils, occluder devices, vascular plugs and even bypass. Naturally, invasive surgical intervention is difficult to justify in asymptomatic patients.

Yip AMC and Al have summarized published outcomes of interventions for post-cardiac transplant CAF [6]. The decision to act was based on the development of symptoms for the majority of patients.

To our knowledge, our case is the third report of a myocardial biopsy causing myocardial infarction worldwide. The first case report was a heart transplant patient who had undergone several EMB, and whom its TTE revealed severe left ventricular dysfunction after a stroke. Coronary angiography showed distal LAD fistula to the right ventricle. Left ventricular angiogram showed apical dyskinesia. Electrocardiogram and angiographic changes were thought to be due to a myocardial infarction secondary to a post-EMB hematoma [9].

The second case was reported in a patient presenting with acute myocardial infarction immediately post-EMB. A PTFE covered stent $3.0 \times 12$ mm (Jostent Coronary Stent Graft, Jomed, Germany) was percutaneously deployed, thus completely sealing off the fistula [10]. 


\section{CONCLUSION}

Post-transplant CAF are more common in EMB than it is recognized, which is why routine screening should be considered. Our case shows that an acute myocardial infarction caused by coronary steal phenomenon resulting from a coronary fistula constitutes a life threatening complication of EMB. Percutaneous implantation of a covered stent was an effective therapy in this case. Cardiac MRI displays excellent negative predictive capacity for diagnosis of cardiac allograft rejection and promise to reduce the EMB requirement in cardiac transplant rejection surveillance [11].

\section{REFERENCES}

1. Henzlova MJ, Nath H, Bucy RP, Bourge RC, Kirklin JK, Rogers WJ. Coronary artery to right ventricle fistula in heart transplant recipients: a complication of endomyocardial biopsy. Journal of the American College of Cardiology. 1989 Jul 1;14(1):258-61.

2. Lazar JM, Uretsky BF. Coronary artery fistula after heart transplantation: a disappearing entity?. Catheterization and cardiovascular diagnosis. 1996 Jan;37(1):10-3.

3. Costanzo MR, Dipchand A, Starling R, Anderson A, Chan M, Desai S, Fedson S, Fisher P, GonzalesStawinski G, Martinelli L, McGiffin D. The International Society of Heart and Lung Transplantation Guidelines for the care of heart transplant recipients.

4. Acharya D, Litovsky S, Papapietro SE, Pamboukian SV, Tallaj JA. Coronary artery fistula after cardiac transplantation. Circulation. 2012 Oct $23 ; 126(17): 2144-5$.
5. Yamanaka O, Hobbs RE. Coronary artery anomalies in 126,595 patients undergoing coronary arteriography. Catheterization and cardiovascular diagnosis. 1990 Sep;21(1):28-40.

6. Yip AMC, Chong AY, Stadnick E, Davies RA, Haddad H, Mielniczuk LM and Sharon Chih, Treatment of Coronary Artery Fistula Post-Cardiac Transplantation with Covered Stent: A Case Study and Review of Literature International Journal of Transplantation Research and Medicine, literature review; 3(2).

7. Wallner M, Zweiker R, Maier R, Strunk D, von Lewinski D. Massive fistulization into the left ventricle of a transplanted heart. Herz. 2015 Mar $1 ; 40(1): 56-8$.

8. Gowda RM, Vasavada BC, Khan IA. Coronary artery fistulas: clinical and therapeutic considerations. International journal of cardiology. 2006 Feb 8;107(1):7-10.

9. Drobinski G, Dorent R, Ghossoub JJ, Collet JP, Choussat R, Montalescot G, Thomas D, Gandjbackch I. Myocardial infarction after endomyocardial biopsy in a heart transplant patient. Journal of interventional cardiology. 2002 Oct;15(5):403-5.

10. Lee CH, Lemos Neto P, Serruys P. Acquired coronary artery fistula leading to acute myocardial infarction after endomyocardial biopsy. Heart. 2003 Jan 1;89(5):495-.

11. Imran M, Wang L, McCrohon J, Yu C, Holloway C, Otton J, Huang J, Stehning C, Moffat KJ, Ross J, Puntmann VO. Native T1 mapping in the diagnosis of cardiac allograft rejection: a prospective histologically validated study. JACC: Cardiovascular Imaging. 2019 Aug 5;12(8 Part 2):1618-28. 